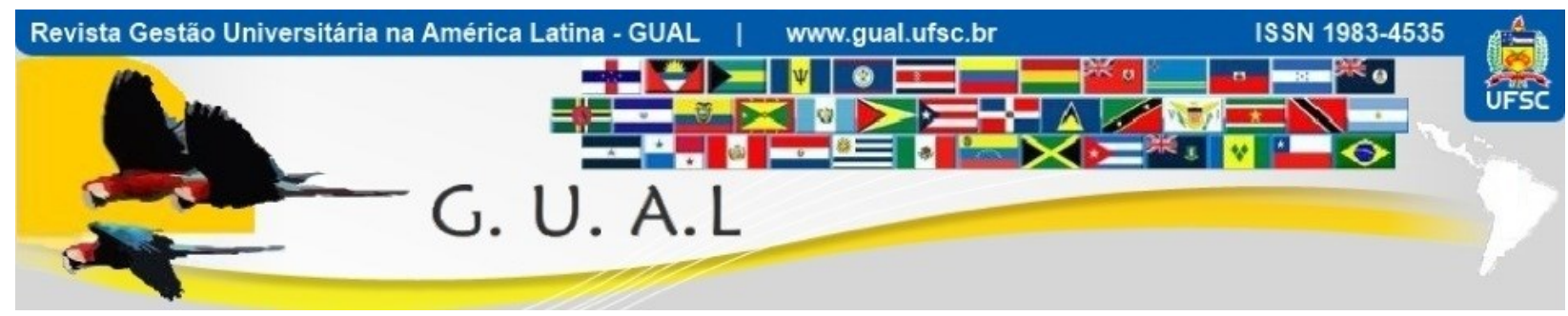

DOI: http://dx.doi.org/10.5007/1983-4535.2018v11n3p63

\title{
LIÇÕES APRENDIDAS EM PROJETOS COMO ESTRATÉGIA DE SISTEMATIZAÇÃO DO CONHECIMENTO ORGANIZACIONAL: UM ESTUDO DE CASO DE UMA UNIVERSIDADE PÚBLICA FEDERAL
}

\section{LESSONS LEARNED IN PROJECTS AS A STRATEGY OF SYSTEMATIZATION OF ORGANIZATIONAL KNOWLEDGE: A CASE OF A FEDERAL PUBLIC UNIVERSITY}

Fábio Silva Figueiredo, Mestre Universidade Federal de Juiz de Fora - UFJF fabio.figueiredo@ufjf.edu.br

Américo Costa Ramos Filho, Doutor Universidade Federal Fluminense - UFF americoramos@id.uff.br

Recebido em 05/julho/2017

Aprovado em 05/agosto/2018

Sistema de Avaliação: Double Blind Review

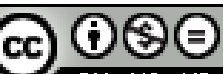

Esta obra está sob uma Licença Creative Commons Atribuição-Uso. 


\title{
RESUMO
}

Gerenciar o Conhecimento organizacional ainda é desafiador para as organizações públicas atuais: gerenciá-lo em projetos de Consultoria Interna pode ser ainda mais trabalhoso. A organização estudada é uma Universidade Pública Federal, que enfrentou um grande crescimento organizacional nos últimos anos. Para acompanhar esse desenvolvimento, esta organização adotou uma estratégia de gestão baseada em Consultoria Interna. Esse modelo trouxe consigo, além dos benefícios próprios da Consultoria Interna, um expressivo aumento do conhecimento organizacional que passou a ser rotineiramente criado por essa equipe. Assim, percebeu-se uma lacuna estratégica na determinação de uma ferramenta que fosse capaz de sistematizar este conhecimento. Tendo como base o modelo de conversão do conhecimento de Nonaka e Takeuchi (1997), buscou-se investigar como os projetos de consultoria podem se valer da prática de lições aprendidas para a efetiva Gestão do Conhecimento no âmbito desses projetos. A pesquisa é um estudo de caso único, aplicada, descritiva e qualitativa. Identificou-se que a aplicação das lições aprendidas à Gestão do Conhecimento está intrinsecamente ligada à dinâmica de interação entre o conhecimento tácito e explícito que esta prática pode proporcionar. A conclusão do estudo é que as lições aprendidas sistematizam o conhecimento em equipes de consultoria no momento em que esta é uma ferramenta capaz de criar uma dinâmica de interações entre os indivíduos que perpassa toda a espiral de criação do conhecimento em um movimento ascendente e contínuo.

Palavras chave: Administração Pública. Consultoria Interna. Gestão do Conhecimento. Gestão de Projetos. Lições Aprendidas.

\begin{abstract}
Managing the Organizational Knowledge is still a challenge to the current public organizations: manage it in internal consulting projects can be even more laborious. The organization studied is a Federal Public University, which has faced great organizational growth in recent years. To follow this development, this organization adopted a management strategy based on internal consulting. This model brought with it, in addition to the benefits of internal consulting, a significant increasing in organizational knowledge that has been routinely created by this team. Thus, a strategic gap in the determination of a tool capable of systematizing this knowledge was perceived. Based on the knowledge conversion model of Nonaka and Takeuchi (1997), we sought to investigate how consulting projects can use the practice of lessons learned for the effective knowledge management within these projects. The research is a unique, applied, descriptive and qualitative case study. It was identified that the application of lessons learned to knowledge management is intrinsically linked to the dynamics interaction between tacit and explicit knowledge that this practice can provide. The conclusion of the study is that the lessons learned systematize the knowledge in consulting teams at the moment this is a tool able to create a dynamic interactions between the individuals that crosses the whole spiral of knowledge creation in an upward and continuous movement.
\end{abstract}

Keywords: Public Management. Internal Consulting. Knowledge Management. Project Management. Lessons Learned. 


\section{INTRODUÇÃO}

Cada vez mais a importância do conhecimento vem sendo discutida tanto no universo das organizações públicas quanto nas organizações privadas, de forma a se reconhecer o grande valor que este ativo intangível tem para as organizações. No ambiente de negócios, Drucker (1993) afirma que dada a sua relevância, as organizações necessitam urgentemente de instrumentos que possam orientá-las na efetiva utilização deste recurso.

Por outro lado, tendo em vista a natureza multidisciplinar da Gestão do Conhecimento, é possível associá-la com diversas outras áreas do saber igualmente relevantes, como a inovação, o aprendizado, a tecnologia da informação e até mesmo a Gestão de Projetos.

Nesse sentido, existe uma relação íntima entre a Gestão do Conhecimento e a Gestão de Projetos, visto que os processos de gerenciamento de projetos geram uma significativa gama de conhecimento organizacional. E é, justamente, no processo de encerramento que é gerada a maior carga de conhecimento.

É nesta fase que, segundo o PMBOK - Project Management Body of Knowledge (PMI, 2013), são gerados os ativos de processos organizacionais. Estes ativos podem ser entendidos como fatores que auxiliam no sucesso do projeto, na medida em que representam todo o conhecimento adquirido em projetos anteriores e é nessa base de conhecimento que se encontram as lições aprendidas.

É nesse contexto que o presente estudo se desenvolve. A Instituição Federal de Ensino Superior objeto deste estudo teve um expressivo crescimento em suas atividades. Essa expansão física, acadêmica e pedagógica acabou sendo refletida na sua estrutura organizacional, a qual teve seus processos de gestão aumentados em um curto período de tempo, representando uma série de novos desafios para os gestores desta organização.

Para lidar com esse rápido crescimento que levou a condição de gestão desta instituição pública a uma necessária modernização, o Setor de Planejamento adotou, a partir de 2011, uma estratégia de gestão na qual os Administradores seriam todos lotados neste setor a fim de compor uma equipe de consultoria, a qual passaria a ser responsável por prestar Consultoria Interna por meio de projetos específicos voltados aos setores demandantes.

Tais consultorias tomariam forma por meio de projetos e versariam sobre demandas administrativas complexas, como compras de grande vulto, estudos de reestruturação administrativa e outras demandas que exigiriam análises mais aprofundadas para a sua correta solução. Iniciam-se então, os trabalhos de Consultoria Interna que se mostraram como "uma 
alternativa viável para o desenvolvimento organizacional" tendo como objetivo "responder de maneira ágil e inteligente às necessidades organizacionais" (MANCIA, 1997, p. 16).

Por outro lado, este modelo de gestão, ainda que tenha trazido uma série de benefícios à organização, como redução de custos operacionais, soluções adequadas aos problemas dentro da realidade da organização e respostas mais rápidas e precisas para problemas emergenciais, trouxe consigo também um expressivo aumento do conhecimento organizacional que passou a ser rotineiramente criado por essa equipe.

Partindo-se da premissa de que o conhecimento se mostra como um dos principais ativos das organizações (DAVENPORT e PRUSAK, 2003), percebeu-se uma lacuna estratégica na determinação de uma ferramenta que fosse capaz de sistematizar este conhecimento organizacional criado por meio desses projetos de Consultoria Interna, de forma a contribuir com a socialização, externalização, combinação, internalização desse conhecimento organizacional.

Tendo como base o modelo de conversão do conhecimento - modelo SECI - de Nonaka e Takeuchi (1997) e partindo do pressuposto de que a prática de lições aprendidas é determinante e crítica para a sistematização do conhecimento organizacional desenvolvido em projetos elaborados por equipes de Consultoria Interna, chegou-se à formulação da seguinte questão de pesquisa: como a prática de lições aprendidas poderia sistematizar o conhecimento organizacional em projetos desenvolvidos por uma equipe de Consultoria Interna em uma Instituição Federal de Ensino Superior?

O presente estudo estrutura-se da maneira a seguir. Após essa seção de Introdução, na qual é caracterizado a organização e o problema de pesquisa, tem-se a Revisão de Literatura, com uma breve exposição sobre a Administração Pública Brasileira, a Consultoria Administrativa, a Gestão de Projetos e a Gestão do Conhecimento organizacional. Posteriormente, expõe-se a Metodologia e o Estudo de Caso. Na sequência, na seção de Análise dos Dados, apresenta-se a descrição das categorias e a análise dos dados. Por fim, a Conclusão encerra o trabalho resgatando os resultados da pesquisa e propõe sugestões para novos estudos. 


\section{A ADMINISTRAÇÃO PÚBLICA BRASILEIRA}

Para Daft (2010 p. 6) a administração pode ser definida como o "o atingimento das metas organizacionais de modo eficiente e eficaz por meio do planejamento, organização, liderança e controle dos recursos organizacionais".

No âmbito público, Castro (2006) argumenta que a Ciência da Administração não está só, mas conectada a elementos oriundos da Ciência Jurídica, visto que nesse contexto, a Administração Pública deve atuar em função das normas jurídicas que a estabelece, de modo que ao administrador público só resta fazer aquilo que é determinado por lei, conforme determina o Princípio da Legalidade.

Mello (2011) e Meirelles (2013) acrescentam que, quando se fala em Administração Pública, fala-se em um conjunto de funções desempenhadas pelo Estado para a consecução dos seus objetivos, que em última instância está em atender as necessidades da coletividade. Não somente nas funções, mas também no conjunto de normas e leis que se prestam a esta função. Além do que, pode-se relacionar o termo à gestão do aparelhamento do Estado, de forma a dirigi-lo e organizá-lo para o correto funcionamento dos serviços públicos.

Por outro lado, para uma melhor caracterização do presente estudo, é mister que se localize o momento atual da Administração Pública brasileira. Nesse sentido, focar-se-á na última grande reforma administrativa do Estado que ocorreu na década de 1990, qual seja, a Reforma Gerencial, que buscou superar a ineficiência Estatal por meio de práticas de gestão mais modernas que fossem capazes de quebrar com a rigidez burocrática.

A partir da crise do Estado da década de 1980, aliada às disfunções do Modelo Burocrático, este modelo deixou de surtir os efeitos benéficos para os quais foi implantado. Bresser-Pereira (2008) afirma que essa crise proveio do aumento das demandas sociais, que ampliou o papel do Estado como provedor de bens e serviços públicos, e da crise fiscal, na qual se percebeu que o estado possuía mais demandas do que recursos, necessitando assim de uma nova forma mais ágil, mais flexível e mais eficiente de se administrar a máquina pública, que se contrapusesse às disfunções que se verificaram no escopo da Administração Pública Burocrática (BRESSER-PEREIRA, 2008; ABRÚCIO, 2005).

Nesse cenário, nas duas últimas décadas o governo tem promovido uma série de iniciativas para a modernização da gestão pública em áreas como descentralização, eficiência do gasto público, governo eletrônico, profissionalização de pessoal e transparência pública. 
Nesse sentido, Abrúcio (2005), afirma que a Administração Pública encontra-se num contexto no qual antigas práticas são suplantadas por novas propostas, como a Administração por Objetivos, Empowerment, Retribuição por Desempenho, Qualidade Total e diversas formas de descentralização. Todas essas propostas fazem parte de um conjunto de medidas cuja finalidade é modificar, no nível mais abrangente possível, os parâmetros da organização burocrática (ABRÚCIO, 2005, p. 173-174). Dentro da proposta do presente trabalho, passa-se então a analisar uma dessas novas propostas: a Consultoria Administrativa.

\section{CONSULTORIA ADMINISTRATIVA}

Com a quebra de paradigma de visão fragmentada da organização, típica da Administração Científica, a consultoria tem sido uma das maneiras encontradas pelas organizações para buscar mais agilidade em seus processos de gestão. Essa nova visão sistêmica, posicionou a organização em um contexto mais amplo e o ambiente passou a ter um papel fundamental na determinação de mudanças internas para gerarem respostas ao meio em que estas organizações se inserem (MANCIA, 1997).

Pode-se conceituá-la como "um conjunto de atividades desenvolvidas pelo consultor, que ajudam o cliente a perceber, entender e agir sobre fatos inter-relacionados que ocorrem no seu ambiente" (SCHEIN, 1972, p. 8). Ou como "um processo de solução de problemas, no qual o consultor assiste o cliente para eliminar discrepâncias entre o desempenho observado e o desempenho desejado" (BERGAN, 1976, p. 4).

Com relação ao consultor, Reich (1994) o caracteriza como os responsáveis pela identificação e solução de problemas, trabalhando em equipes, compartilhando problemas e aprendendo pelo exercício da prática, em um processo contínuo de aprendizagem em torno das situações problemáticas do cotidiano.

Em suma, pode-se dizer que a atividade da consultoria desempenha um papel de apoio na resolução de problemas organizacionais em um ambiente de parceria (ajuda mútua) entre consultor e consultado (cliente) num processo contínuo de interação.

Dentre os benefícios inerentes à consultoria está o subsídio à tomada de decisão e aprendizagem mediante o desenvolvimento, compartilhamento e aplicação do conhecimento na melhoria dos processos e no gerenciamento de seus colaboradores, no intuito de fornecer maiores retornos com suas atividades (VIEIRA, FEITOSA e CORREA, 2007). 
No que tange à Consultoria Interna, Johri, Cooper e Prokopenko (1998) identificam nela uma possibilidade de a empresa resolver seus problemas sem ter de criar assessorias permanentes em cada unidade ou contratar serviços de Consultoria Externa. Lacey (1995) acrescenta que a Consultoria Interna pode ser mais vantajosa justamente porque nela o consultor acompanha a implementação das estratégias sugeridas até a conclusão do trabalho.

Por fim, Freitag (2012) discorre sobre o potencial que a prática da Consultoria Interna tem de criar e converter conhecimento em uma organização. Seu estudo aponta que em virtude da função maior da Consultoria Interna ser a resolução de problemas organizacionais e também em virtude das interações entre os profissionais, o consultor acaba sendo demandado a desenvolver habilidades para lidar com a diversidade de aspectos que essas interações compreendem, gerando uma grande gama de conhecimento.

Mas, como transpor os limites funcionais e organizacionais estabelecidos pelas estruturas hierárquicas tradicionais (verticalizadas e inflexíveis), muito comuns na Administração Pública brasileira e unir a estratégia de utilização de equipes de Consultoria Interna ao cotidiano operacional das instituições públicas?

Segundo Cleland e Ireland (2007, p. 7), a Gestão de Projetos tornou-se o principal meio para o gerenciamento de atividades $a d h_{o c}{ }^{1}$ nas organizações, tal qual a Consultoria Interna, apresentando-se como uma "alternativa estratégica para o atendimento de problemas emergenciais visando o uso de equipes alternativas na administração operacional e estratégica da organização". Assim, apresenta-se como uma tática gerencial adequada para a implantação da Consultoria Interna no âmbito de organizações públicas e privadas.

\section{GESTÃO DE PROJETOS}

O Guia PMBOK - 5 edição (PMI, 2013, p. 3) define projeto como "um esforço temporário empreendido para criar um produto, serviço ou resultado exclusivo". Kerzner (2006), o define como um empreendimento único com início e fim claramente definidos, com objetivo bem delimitado, que consome recursos, tem um escopo especificado e opera sob pressões de prazo, custo e qualidade.

\footnotetext{
${ }^{1}$ Aquilo que se destina a um fim específico. Em Administração, este termo está ligado à adhocracia, que estabelece modelos de gestão de empresas baseadas em projetos. É caracterizada pela utilização de equipes multidisciplinares, que cooperam entre si para se alcançar um determinado objetivo. É qualquer forma organizacional que conteste a burocracia para se alcançar algo novo, que incentive a mudança e envolva equipes de projetos ou força-tarefa, tendo forte impacto na Gestão do Conhecimento (WATERMAN JR., 1992).
} 
A crescente aceitação do gerenciamento de projetos indica que a aplicação de conhecimentos, processos, habilidades, ferramentas e técnicas adequadas pode ter um impacto significativo no sucesso de um projeto (PMI, 2013). Kezner (2006) aponta a necessidade de uma metodologia empresarial e o planejamento efetivo como fatores críticos no ciclo de vida da Gestão de Projetos.

Como uma referência básica ${ }^{2}$, o PMBOK (PMI, 2013) se baseia em processos e subprocessos para descrever de forma organizada o trabalho a ser realizado durante o ciclo de vida de um projeto. Os processos descritos se relacionam durante a condução do trabalho e a descrição de cada um deles é feita em termos de: entradas; ferramentas e técnicas e saídas.

Nesse sentido, os Ativos de Processos Organizacionais podem ser entendidos como fatores que ajudam na gestão e no sucesso do projeto na medida em que representam o conhecimento que a organização obteve ao longo da realização de projetos.

O PMBOK (PMI, 2013) é enfático ao assegurar que os ativos de processos organizacionais incluem as bases de conhecimento sobre as quais os projetos da organização estão estruturados, sendo constituídos de dados sobre riscos e valor agregado, cronogramas, planos de comunicação, planos de gerenciamento de projetos, mapas de risco, orçamentos e outros; mas, sobretudo são constituídos pelas lições aprendidas e informações históricas.

Segundo o PMBOK (PMI, 2013), os ativos de processos organizacionais podem ser agrupados em duas categorias: (1) processos e procedimentos; (2) base de conhecimento corporativo. A primeira categoria inclui os processos e procedimentos da organização para a condução do trabalho do projeto; já a segunda categoria inclui a base de conhecimento organizacional corporativa para o armazenamento e recuperação de informações.

Vê-se a importância da prática de lições aprendidas na sistemática da Gestão de Projetos, no momento em que essas práticas estão presentes nas duas categorias de ativos de processos organizacionais sendo, portanto, fundamentais para agregar valor aos projetos desempenhados pela organização e gerar conhecimento organizacional relevante.

Gouveia, Montalvão e Brito (2010, p.16) definem lições aprendidas como "narrativas que explicitam conhecimentos ou um entendimento adquirido através de uma experiência, que pode ser tanto positiva como negativa" acrescentando que a gestão de lições aprendidas é uma forma de aplicar o conhecimento do capital humano obtido através de experiências em

\footnotetext{
${ }^{2}$ A escolha pelo PMBOK (PMI, 2013) como referência básica para a Gestão de Projetos nesta pesquisa se deu pelo fato de este Guia ser uma literatura consolidada tanto na área acadêmica quanto na área profissional e de conhecimento tanto dos pesquisadores, quanto dos sujeitos da pesquisa.
} 
projetos anteriores, de forma que erros cometidos em outros projetos podem ser evitados e práticas bem sucedidas podem melhorar o resultado do projeto presente. Nesse sentido, a Gestão do Conhecimento é um conjunto de técnicas cujo objetivo é apoiar a criação, a transferência e a aplicação do conhecimento nas organizações, conforme se verá a seguir.

\section{A GESTÃO DO CONHECIMENTO}

Em uma organização moderna, a sua competência competitiva está muito mais nas suas capacidades intelectuais e de serviço do que necessariamente em seus ativos imobilizados como terras, equipamentos e instalações produtivas (DRUCKER, 1993).

No contexto organizacional, o conhecimento adquire status de recurso estratégico, capaz de sustentar a vantagem competitiva das organizações. O sucesso passa a ser resultado da mobilização desse recurso de forma a enfrentar um novo ambiente de negócios.

Assim, a Gestão do Conhecimento pode ser considerada como um "sistema integrado que visa desenvolver conhecimento e competência coletiva para ampliar o capital intelectual de organizações e a sabedoria das pessoas" (SABBAG, 2007, p. 60).

Nonaka e Takeuchi (1997) afirmam que no cerne desta questão está a aquisição, o acúmulo e a utilização do conhecimento existente dentro da perspectiva de criação do conhecimento. Para explicar a teoria da Criação do Conhecimento organizacional, esses autores partem de uma abordagem epistemológica na qual o conhecimento se cria a partir da mobilização e conversão do conhecimento tácito em explícito.

O conhecimento tácito, não é facilmente visível. Ao contrário, é altamente pessoal e difícil de formalizar, tornando as comunicações e o compartilhamento dificultoso. Este está profundamente enraizado na experiência do indivíduo, assim como nos seus ideais, valores e crenças (NONAKA E TAKEUCHI, 2008). Em virtude dessa subjetividade do conhecimento tácito, esses valores determinam, em grande medida, aquilo que o conhecedor vê, absorve e conclui a partir de suas observações (DAVENPORT e PRUSAK, 2003).

Já o conhecimento explícito pode ser expresso em palavras e números, e compartilhado na forma de dados, fórmulas, recursos visuais, especificações de produtos ou manuais. O conhecimento explícito pode ser rapidamente transmitido aos indivíduos, formal e sistematicamente (NONAKA E TAKEUCHI, 2008).

Dados os conceitos iniciais, segundo Nonaka e Takeuchi (1997), o modelo dinâmico da criação do conhecimento está fundamentado no pressuposto de que o conhecimento 
humano é criado e expandido por meio da interação entre o conhecimento tácito e o conhecimento explícito, chamada de Conversão do Conhecimento (NONAKA E TAKEUCHI, 1997).

A partir da interação entre conhecimento tácito e explícito, Nonaka e Takeuchi (1997) propuseram quatro modos de conversão do conhecimento em um processo de transformação interativo e em espiral. São eles: a socialização que é a conversão do conhecimento tácito em conhecimento tácito; a externalização que é a conversão do conhecimento tácito em explícito; a combinação que é a conversão do conhecimento explícito em conhecimento explícito; a internalização que é a conversão do conhecimento explícito em conhecimento tácito.

A socialização ocorre de indivíduo para o indivíduo; a externalização acontece no nível de indivíduo para o grupo; a combinação no nível do grupo para a organização e a internalização no nível da organização para o indivíduo (NONAKA E TAKEUCHI, 2008).

A dinâmica de conversão do conhecimento se dá através de um ciclo também conhecido como modelo SECI, (Socialização-Externalização-Combinação-Internalização). Este modelo pode ser observado na figura a seguir:

Figura 1 Quatro modos de conversão do conhecimento

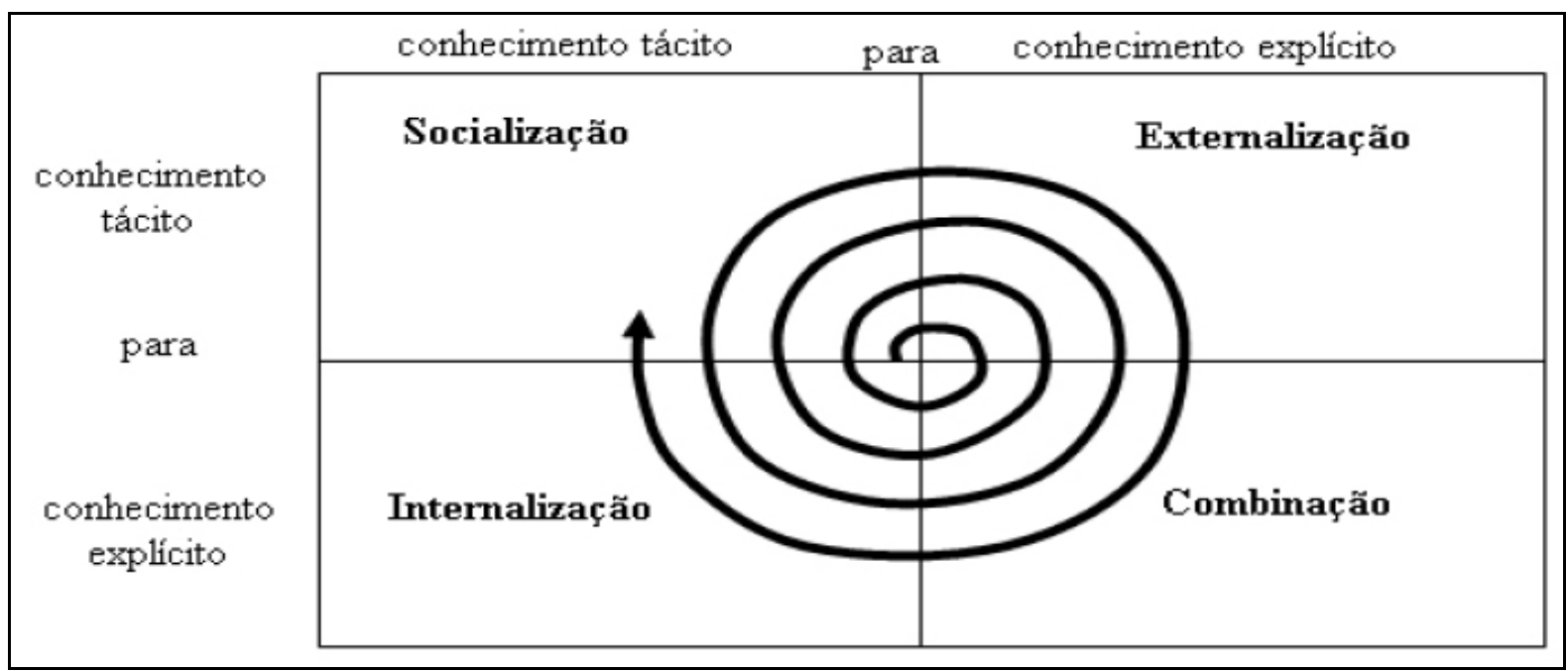

Fonte: adaptado de Nonaka e Takeuchi, 1997.

\subsection{A GESTÃO DO CONHECIMENTO EM ORGANIZAÇÕES PÚBLICAS}

No contexto de reformulação da gestão pública brasileira, na qual o modelo gerencial promove mudanças progressivas nos valores e, principalmente, nas práticas de gestão (SECCHI, 2009), a Gestão do Conhecimento desponta como um instrumento hábil para tornar a máquina administrativa mais eficiente e eficaz. 
Coelho (2004, p. 110) afirma que, apesar de as organizações públicas possuírem propósitos distintos das organizações privadas (estas vinculam eficiência administrativa à lucratividade; aquelas a vinculam ao perfeito atendimento das demandas da sociedade), "atualmente, as estratégias e tecnologias utilizadas para a consecução de seus objetivos tendem a ser semelhantes" (COELHO, 2004, p. 111).

Dessa forma, em uma visão estratégica, percebe-se que gerir o conhecimento organizacional de forma a tornar a organização mais produtiva, constitui um requisito fundamental para a boa gestão pública, para que estas organizações mantenham-se inovadoras, eficientes e entreguem um serviço de alto valor à sociedade.

$\mathrm{Na}$ Administração Pública, a Gestão do Conhecimento tem uma finalidade bastante ampla. Ela aumenta a efetividade das ações públicas, transcendendo "a finalidade de melhorar o desempenho organizacional, cumprindo importante função na sociedade democrática e na inserção do país na economia mundial” (BATISTA, 2004, p. 10).

\subsection{A GESTÃO DO CONHECIMENTO EM PROJETOS}

Na medida em que o conhecimento é reconhecido como novo recurso organizacional, paralelamente, ele pode ser reconhecido como um novo recurso do projeto, se convertendo em um fator crítico de sucesso para o próprio projeto.

Brasil e Tabares (2012) afirmam que as disciplinas da Gestão do Conhecimento e da Gestão de Projetos podem agir sinergicamente contribuindo para a conclusão dos objetivos organizacionais. A aplicação integrada dessas duas disciplinas impacta positivamente em todos os setores da organização, ampliando a possibilidade de sucesso do negócio.

Assim, percebe-se que a Gestão do Conhecimento em projetos é um assunto que vem ganhando espaço devido à necessidade do estabelecimento de práticas de Gestão do Conhecimento intra e inter-projetos que possibilitem a troca de experiências.

Terra (2001) salienta que os projetos são ricos em conhecimento, pois o aprendizado, tanto das pessoas quanto das organizações, se dá no decorrer dos projetos, sugerindo uma série de medidas que facilitam esse aprendizado.

Comprova-se, então, que é essencial gerir todo esse conhecimento, pois, quando bem gerido, melhora a agilidade dos projetos, cria um ambiente contínuo de inovação, aumenta a produtividade da equipe e melhora a qualidade da tomada de decisão nos projetos. 
5.3 A PRÁTICA DE LIÇÕES APRENDIDAS COMO ESTRATÉGIA DE SISTEMATIZAÇÃO DO CONHECIMENTO ORGANIZACIONAL EM PROJETOS

A ideia de adquirir conhecimento com a experiência alheia ou aprender com experiências anteriores tem levado muitas organizações a implantarem sistemas de lições aprendidas.

Esta visão de 'aprender com a experiência' tem levado muitas empresas a criarem um processo de lições aprendidas, de modo que se algo não vai de acordo com o plano, eles esperam que a empresa como um todo reflita sobre o que aconteceu e desenhe lições do passado, a fim de não repeti-las no futuro (MILTON, 2010, p. 2).

Partindo do pressuposto de que sob a óptica da Gestão do Conhecimento toda e qualquer experiência é conhecimento, Ferenhof, Forcellini, Varvakis (2013), correlacionam a prática de lições aprendidas ao conhecimento, de forma que ela está relacionada com experiências-chave que contêm alguma relevância para o projeto (presente ou futuros) e que, portanto, devem ser explicitadas, compartilhadas e disseminadas a fim de agregar valor às pessoas e à organização.

Davenport e Prusak (2003) argumentam que o conhecimento profissional é adquirido por meio de tentativa e erro no decorrer de uma longa experiência e observação. Assim, as lições aprendidas podem servir de atalhos para soluções de novos problemas que relembram problemas já solucionados. Profissionais experientes podem enxergar certos padrões já conhecidos em situações novas e responder mais rapidamente e de forma mais apropriada. Em outras palavras, o conhecimento acumulado e compartilhado em lições aprendidas pode oferecer maior velocidade de resposta. São eficientes guias para situações complexas, atuando como padrões de experiência interiorizada.

A prática de lições aprendidas pode, portanto, ajudar a mitigar os riscos de um projeto, a fim de se obter uma melhor compreensão das atividades envolvidas, melhorando sistematicamente os processos de Gestão do Conhecimento, aumentando o uso sistemático das competências dos envolvidos e identificando a causa raiz de sucessos e fracassos, de forma a contribuir com a eficiência dos processos organizacionais (FERENHOF; FORCELLINI; VARVAKIS, 2013).

Dessa forma, tendo por base este referencial teórico, passa-se ao próximo capítulo que irá abranger o percurso metodológico adotado na elaboração da pesquisa a fim de encontrar respostas à problemática apresentada. 


\section{PROCEDIMENTOS METODOLÓGICOS}

O presente trabalho é de natureza qualitativa, o que significa que "é orientado para a análise de casos concretos em sua particularidade temporal e local, partindo das expressões e atividades das pessoas em seus contextos locais" (FLICK, 2004, p. 28).

Quanto aos fins, é aplicado e descritivo. Aplicado, pois busca resolver problemas concretos e com finalidade prática; descritivo, pois expõe características de determinada população ou determinado fenômeno (VERGARA, 2009).

Quanto aos meios, a presente pesquisa é: pesquisa de campo, documental, bibliográfica e estudo de caso. É pesquisa de campo, visto que é uma investigação empírica, na qual o autor coleta informações sobre o fenômeno em campo; é documental em virtude de utilizar documentos organizacionais usados pelos sujeitos da pesquisa; é bibliográfica uma vez que, para construção do referencial teórico e contextualização do caso, foram utilizadas diversas fontes de consulta, como livros, artigos científicos e periódicos; por fim, é estudo de caso, visto que são estudados os 30 projetos de consultoria realizados por estes sujeitos desde a criação da equipe em janeiro de 2010 até dezembro de 2015.

A investigação teve caráter individual e os sujeitos pesquisados são os seis Administradores lotados no Setor de Planejamento desta instituição e que trabalham diretamente na equipe de consultoria, sendo que este número representa a totalidade do universo pesquisado. A idade média dos entrevistados é de 35 anos; há apenas uma mulher na equipe e o tempo médio de trabalho na equipe é de três anos. Três deles possuem mestrado e três, especialização.

Como ferramenta de coleta de dados, utilizou-se a entrevista individual com roteiro semiestruturado (VERGARA, 2009). O roteiro foi elaborado a partir dos conceitos prédefinidos no referencial teórico, perpassando os objetivos do estudo e dividiu-se em três blocos: a) o $1^{\mathrm{o}}$ bloco procurou compreender as percepções do entrevistado sobre os projetos de Consultoria Interna elaborados pela equipe; b) o $2^{\circ}$ bloco buscou captar do entrevistado sua compreensão sobre a Gestão do Conhecimento, do conhecimento organizacional e como este conhecimento organizacional pode ser criado/adquirido pela organização; c) no $3^{\circ}$ bloco, finalmente, buscou-se compreender, aprofundadamente, na visão do entrevistado, qual a aplicabilidade da Gestão do Conhecimento aos projetos de consultoria interna desenvolvidos pela equipe. As seis entrevistas, foram realizadas ao longo dos primeiros meses de 2016, todas no local de trabalho dos indivíduos. 
O modelo de análise de dados utilizado nesta pesquisa foi a análise indutiva proposta por Thomas (2006, p. 238) a qual o autor a descreve como "um procedimento sistemático para a análise de dados qualitativos, em que a análise deve ser guiada por objetivos específicos de avaliação".

O pressuposto fundamental deste método consiste em que os dados emirjam de temas recorrentes encontrados nos dados brutos, sendo estes frequentes, dominantes ou significantes (THOMAS, 2006). O resultado de uma análise indutiva, segundo Thomas (2006, p. 240) é "o desenvolvimento de categorias em um modelo ou quadro que resume os dados brutos e transmite temas e processos-chave".

Seguindo o processo de codificação da Análise Indutiva de Thomas (2006), os dados foram tratados e comparando-os com a teoria, chegou-se ao seguinte resultado:

Figura 2 Processo de codificação em análise indutiva segundo Thomas (2006)

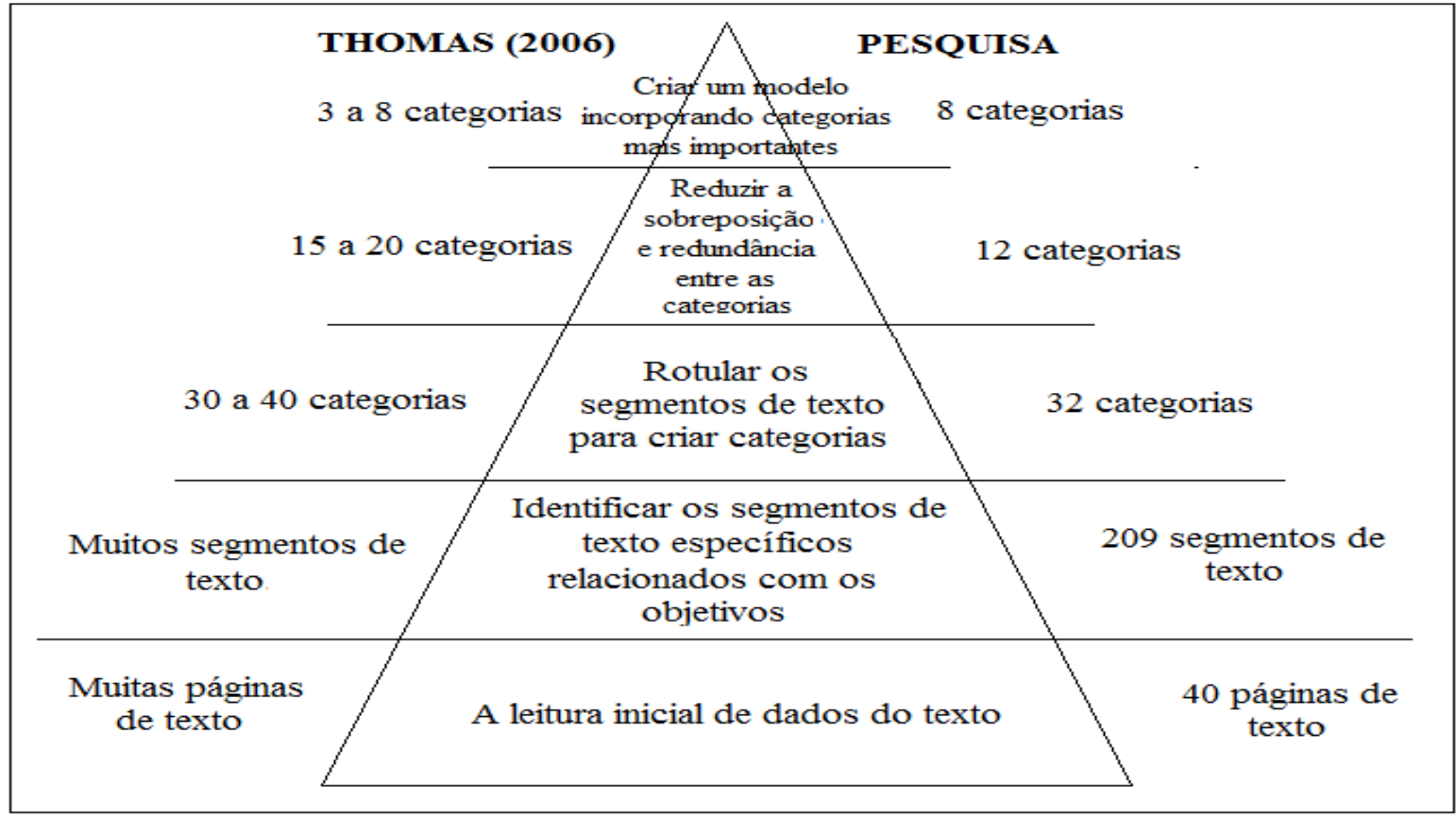

Fonte: adaptado de Thomas (2006)

Após essa análise, à luz da fundamentação teórica, os resultados encontrados foram confrontados com a teoria presente no referencial teórico pesquisado, utilizando-se para isso a contribuição da Correspondência de Padrão (Pattern Matching) proposta por Trochim (1989) que segundo o autor "envolve uma tentativa de ligar dois padrões em que um é o padrão teórico e o outro é o padrão observado ou operacional" (TROCHIM, 1989, p. 356). 


\section{O ESTUDO DE CASO}

A Instituição Federal de Ensino Superior (IFES), objeto deste estudo, localiza-se na região sudeste do Brasil. Atualmente, além do campus sede, possui um campus avançado, também no sudeste do Brasil. Segundo dados do Censo da Educação Superior, esta instituição possui hoje quase 6.000 vagas na graduação, sendo aproximadamente 4.500 na educação presencial e 1.500 na educação a distância; mais de 1.500 docentes e aproximadamente 1.150 Técnicos Administrativos em Educação.

O Setor de Planejamento se organiza como uma Pró-reitoria Adjunta, vinculada a uma Pró-reitoria "mãe" que se responsabiliza pela administração geral da instituição. Ao Setor de Planejamento, além de atividades rotineiras, como gestão e físcalização dos contratos sob sua responsabilidade, cabem as consultorias administrativas aos diversos órgãos desta universidade que são o objeto desta pesquisa.

Essa equipe foi criada no início de 2011, com as novas contratações de Administradores, realizadas por meio de concurso público. Em princípio, a equipe era composta por quatro Administradores, chegando a ter doze componentes, mas, em média, teve um número de oito consultores, todos efetivos e ocupantes do cargo de Administrador.

Os trabalhos se desenvolvem por meio de projetos de consultoria nos quais os consultores se dividem em grupos e os escolhem por meio de afinidade ou competência técnica/comportamental para aquela demanda. Assim, alguns consultores se "especializaram" em projetos relacionados a compras públicas de grande vulto, por exemplo; outros, em projetos relacionados à mapeamento/modelagem de processos para reestruturação de setores; e ainda aqueles que se "especializaram" em projetos de planejamento organizacional. Não existe um número mínimo ou máximo de projetos em andamento nem qualquer restrição sobre quantos e quais projetos cada consultor pode participar simultaneamente.

A natureza dos projetos é variável ao longo dos anos e a equipe, ainda que alguns membros tivessem se "especializado" em determinadas demandas, sempre se revezava, proporcionando trocas de experiência e conhecimento entre os membros da equipe.

É importante ressaltar que nenhuma prática sistemática de Gestão do Conhecimento era realizada, tampouco incentivada pelo gestor da equipe ou pela Administração Superior do órgão, não obstante, periodicamente, eram realizadas reuniões para troca de experiências, a fim de que todos pudessem compartilhar dificuldades e êxitos em seus projetos e também para a apresentação de resultados e troca de informações importantes entre os membros da equipe. 


\section{ANÁLISE DOS DADOS}

Este capítulo apresenta a análise dos resultados obtidos a partir das seis entrevistas realizadas. A análise será apresentada a partir das categorias e subcategorias criadas, conforme quadro 1 seguindo processo explicado na figura 2 .

Quadro 1 Categorias e subcategorias criadas a partir da Análise dos Dados

\begin{tabular}{|c|c|}
\hline \multicolumn{2}{|c|}{$1^{\circ}$ Bloco - Projetos de Consultoria Interna } \\
\hline Categorias & $\begin{array}{r}\text { Subcategorias } \\
\end{array}$ \\
\hline \multirow{6}{*}{$\begin{array}{l}1 \text { A relevância dos projetos de consultoria } \\
\text { interna }\end{array}$} & 1.1 Importantes para o dia-a-dia da organização \\
\hline & 1.2 Geradores de eficiência e eficácia administrativa \\
\hline & 1.3 Facilitadores da Gestão do Conhecimento \\
\hline & 1.4 Geradores de economia. \\
\hline & $\begin{array}{l}\text { 1.5 Ferramenta motivacional para os profissionais } \\
\text { consultores }\end{array}$ \\
\hline & 1.6 Como ferramenta para problemas complexos \\
\hline \multicolumn{2}{|c|}{$2^{\circ}$ Bloco - Gestão do Conhecimento } \\
\hline Categorias & Subcategorias \\
\hline \multirow{4}{*}{2 As várias dimensões do conhecimento } & 2.1 Conhecimento $=$ experiência própria \\
\hline & 2.2 Conhecimento $=$ experiência alheia \\
\hline & 2.3 Conhecimento $=$ estudos formais e informais \\
\hline & 2.4 Conhecimento $=$ prática \\
\hline \multirow{4}{*}{$\begin{array}{c}3 \text { As várias dimensões do conhecimento } \\
\text { organizacional }\end{array}$} & 3.1 C.O. = soma de conhecimentos individuais \\
\hline & 3.2 C.O. = soma de experiências "vividas" \\
\hline & 3.3 C.O. = conjunto de informações \\
\hline & 3.4 C.O. = Conjunto de práticas \\
\hline \multirow{2}{*}{4 A aquisição/criação de C.O. } & 4.1 Por meio de pessoas da organização \\
\hline & 4.2 Por meio de estudo/treinamentos/cursos/legislação \\
\hline \multirow{4}{*}{$\begin{array}{l}5 \text { O papel do ciclo de conversão do } \\
\text { conhecimento de Nonaka e Takeuchi na } \\
\text { criação de C. O. }\end{array}$} & 5.1 Socialização \\
\hline & 5.2 Externalização \\
\hline & 5.3 Internalização \\
\hline & 5.4 Combinação \\
\hline \multirow{5}{*}{$\begin{array}{l}6 \text { Ferramentas para a sistematização da } \\
\text { Gestão do Conhecimento }\end{array}$} & 6.1 Treinamentos \\
\hline & $\begin{array}{l}\text { 6.2 Manuais, Procedimento Operacional Padrão } \\
\text { (POP)... }\end{array}$ \\
\hline & 6.3 Ferramentas de TI \\
\hline & 6.4 Mapas de processo, diagramas, fluxogramas... \\
\hline & 6.5 Lições aprendidas \\
\hline \multicolumn{2}{|c|}{$3^{\circ}$ Bloco - Aplicabilidade da Gestão do Conhecimento aos projetos de Consultoria Interna } \\
\hline Categorias & Subcategorias \\
\hline \multirow{4}{*}{$\begin{array}{l}7 \text { Projetos de Consultoria Interna: } \\
\text { geradores de conhecimento }\end{array}$} & 7.1 Por meio de aprendizagem \\
\hline & 7.2 Por meio da prática \\
\hline & 7.3 Por meio da socialização \\
\hline & 7.4 Por meio da externalização \\
\hline \multirow{3}{*}{$\begin{array}{l}8 \text { Ferramentas de GC e Projetos como } \\
\text { sistematizadores do conhecimento } \\
\text { organizacional em projetos de consultoria }\end{array}$} & $\begin{array}{l}\text { 8.1 Socialização (troca de experiências, reuniões, } \\
\text { treinamentos...) }\end{array}$ \\
\hline & 8.2 Externalização (registro e documentação formal) \\
\hline & 8.3 Lições aprendidas \\
\hline
\end{tabular}


Após a análise dos dados de campo, os resultados evidenciam que os projetos de consultoria interna realizados por esta equipe são extremamente relevantes para o dia-a-dia da organização (categoria 1), gerando eficiência e eficácia administrava, além de economia para os cofres públicos. Destaca-se um ponto bastante relatado pelos consultores que diz respeito aos projetos de consultoria enquanto facilitadores da Gestão do Conhecimento. Para eles, os projetos de consultoria, por estarem sempre relacionados a temas complexos, de difícil resolução, sempre contribuem para aumentar o estoque de conhecimento pessoal e organizacional (subcategoria 1.3).

Evidencia-se também que cinco dos seis entrevistados apontaram que esses projetos serviam como ferramentas apropriadas para a resolução de problemas complexos e não rotineiros, conforme sugere a subcategoria 1.6.

Quando questionados em relação à Gestão do Conhecimento (categoria 2), os consultores evidenciaram que não possuíam conhecimento formal sobre o assunto. Para responderem a tal questionamento, todos fizeram correlações na tentativa de explicá-lo. Essas correlações deram origem às subcategorias 2.1 a 2.4. Dessa forma, para eles, o conhecimento se consolida por meio da experiência, própria ou alheia, por meio de estudos, formais ou informais e também por meio da prática.

No que diz respeito ao conhecimento organizacional os entrevistados não formularam respostas baseadas em teorias ou conceitos acadêmicos pré-definidos, de maneira semelhante, fizeram diversas correlações para explicá-lo. Essas correlações deram origem a quatro subcategorias, que definiram o conhecimento organizacional como: a soma de conhecimentos individuais; soma de experiências "vividas"; conjunto de informações e conjunto de práticas (subcategorias 3.1 a 3.4 ).

Ao indagá-los sobre a criação e aquisição de conhecimento organizacional (categoria 4), eles foram unânimes em reconhecer que todo o conhecimento organizacional só pode ser adquirido ou criado por meio das pessoas que trabalham na organização. Entretanto, do ponto de vista prático, dois consultores acrescentaram a possibilidade de criação ou aquisição de conhecimento organizacional por meio de ações de treinamento, cursos, estudos ou conhecimento da legislação, por se tratar de um ambiente de gestão pública, no qual o conhecimento da lei é de extrema importância.

$\mathrm{Na}$ criação de conhecimento organizacional é interessante ressaltar que, mesmo sem conhecer qualquer teoria sobre criação do conhecimento organizacional, somente dois 
entrevistados disseram conhecer a origem conceitual de alguma ferramenta de Gestão do Conhecimento. Grande parte dos entrevistados fizeram importantes correlações entre este tema e o ciclo de conversão do conhecimento de Nonaka e Takeuchi (1997), afirmando que a criação de conhecimento organizacional pode se dar por meio de socialização, externalização, combinação e internalização de conhecimentos, evidenciando assim, o papel do ciclo de conversão do conhecimento de Nonaka e Takeuchi na criação de conhecimento organizacional (categoria 5).

Para fechar o segundo bloco, ainda tratando sobre a Gestão do Conhecimento, os entrevistados foram questionados sobre ferramentas de gestão que poderiam ser úteis para a Gestão do Conhecimento Organizacional (categoria 6). Dentre as ferramentas citadas, estão: treinamentos, manuais e procedimentos operacionais padrão, ferramentas de TI e mapeamento de processos.

Lições aprendidas também foi uma prática que figurou dentre as potenciais ferramentas para a Gestão do Conhecimento Organizacional, sendo afirmada como ferramenta de Gestão do Conhecimento por um Administrador que é também especialista em projetos e por outros dois Administradores, que em virtude de um contato mais profundo com a Gestão de Projetos em outras experiências profissionais, mencionaram essa prática como ferramenta de Gestão do Conhecimento (subcategoria 6.5).

No terceiro bloco de questões, trabalharam-se as questões relativas à aplicabilidade da Gestão do Conhecimento aos projetos de consultoria de forma a criar uma interface entre a Gestão do Conhecimento, a Gestão de Projetos e a Consultoria Interna. Nesse bloco, questionaram-se os entrevistados sobre como esses projetos de consultoria interna poderiam criar conhecimento organizacional e como esse conhecimento poderia ser transmitido ou replicado em outros projetos ou outros setores. Desse modo, originou-se duas importantes categorias de análise: Projetos de consultoria interna: geradores de conhecimento (categoria 7) e Ferramentas de Gestão do Conhecimento e Projetos como sistematizadores do conhecimento organizacional em projetos de consultoria (categoria 8).

Quanto aos projetos de consultoria interna como geradores de conhecimento, foi possível extrair dos entrevistados práticas realizadas por eles que poderiam gerar conhecimento organizacional no desenvolvimento dos projetos de consultoria interna. Dentre elas, destaca-se a aprendizagem, visto que, na grande maioria dos casos, no decorrer do desenvolvimento desses projetos, os consultores são obrigados a buscarem conhecimento 
novo para solucionarem os problemas levantados em cada projeto. Essa aprendizagem também foi destacada pelos entrevistados em forma de realização de cursos, treinamentos, benchmarking, cursos formais lato ou stricto sensu, dentre outros. Também a prática, originada da experiência profissional, foi destacada por dois entrevistados.

Voltou à tona a socialização e a externalização, como geradores de conhecimento organizacional. $\mathrm{Na}$ fala dos entrevistados, fica claro que os indivíduos dessa equipe possuem uma sinergia que os leva a dialogarem constantemente. Nesses diálogos, experiências e práticas dos consultores são compartilhadas o que gera novo conhecimento. Esse conhecimento, se externalizado de alguma forma, acaba sendo utilizado em outro projeto ou é passado para o setor demandante em forma de manual, mapa de processo ou algo parecido.

Por fim, a segunda categoria extraída da análise deste $3^{\circ}$ bloco de questões, versa sobre possíveis ferramentas de Gestão do Conhecimento e/ou Gestão de Projetos que poderiam servir de sistematizadores do conhecimento organizacional nesses projetos de Consultoria Interna. Destaca-se, novamente, a socialização e a externalização agora como ferramentas para sistematização do conhecimento (subcategorias 8.1 e 8.2).

Mais uma vez, também é destacada a prática de lições aprendidas (subcategoria 8.3). Neste momento, reconhece-se as lições aprendidas como importante ferramenta de Gestão do Conhecimento nesses projetos, a fim de se evitar erros futuros e também para discutir possibilidades, acertos e novas abordagens metodológicas para a resolução dos problemas levantados nos projetos.

\section{CONCLUSÕES}

A pesquisa revelou que a criação do conhecimento organizacional está intimamente relacionada ao processo de resolução de problemas complexos que envolve a equipe de consultoria em um processo de melhoria contínua para responder aos desafios que são apresentados à organização. $\mathrm{O}$ esforço empregado na solução destes problemas e o aprendizado de tal processo são socializados pelo grupo acumulando novos conhecimentos e desenvolvendo novas abordagens para a criação do conhecimento organizacional.

O novo conhecimento originado será utilizado em outras partes da organização, a partir do seu compartilhamento. Esse processo se repetirá tantas vezes quantas forem necessárias, estabelecendo assim um ciclo contínuo que sustenta o desenvolvimento organizacional e a criação do conhecimento organizacional. 
Dessa forma, a investigação sobre como os projetos de Consultoria Interna e a Gestão do Conhecimento podem se valer das práticas de lições aprendidas na Gestão do Conhecimento Organizacional nos projetos de consultoria dessa equipe, a pesquisa demonstrou que: (i) a aplicação das lições aprendidas ao processo de sistematização do conhecimento está intrinsecamente ligada à dinâmica da interação entre o conhecimento tácito e explícito que esta prática pode proporcionar, levando à criação de conhecimento organizacional; (ii) a prática de lições aprendidas é um importante ativo de processo que pode, além de evitar erros em projetos futuros, promover a perpetuação de melhores práticas no contexto dessa equipe.

Assim, a prática de lições aprendidas sistematiza a Gestão do Conhecimento em equipes de Consultoria Interna no momento em que esta é uma ferramenta capaz de criar uma dinâmica de interações entre os indivíduos que perpassa toda a espiral de criação do conhecimento em um movimento ascendente e contínuo.

Dessa forma, buscou-se elaborar um modelo analítico para o caso estudado. O modelo apresentado na Figura 3 ilustra a relação desejada entre as práticas de lições aprendidas no contexto de sistematização do conhecimento organizacional em equipes de consultoria interna. Segundo este modelo, a prática de lições aprendidas é capaz de criar um ambiente propício ao compartilhamento de conhecimentos entre os membros da equipe (socialização), fundamental para uma equipe intensiva em conhecimento. Uma vez realizada a socialização, torna-se possível documentar o conhecimento de forma a externalizá-lo para a equipe.

Figura 1 Modelo de lições aprendidas aplicado em equipes de Consultoria Interna

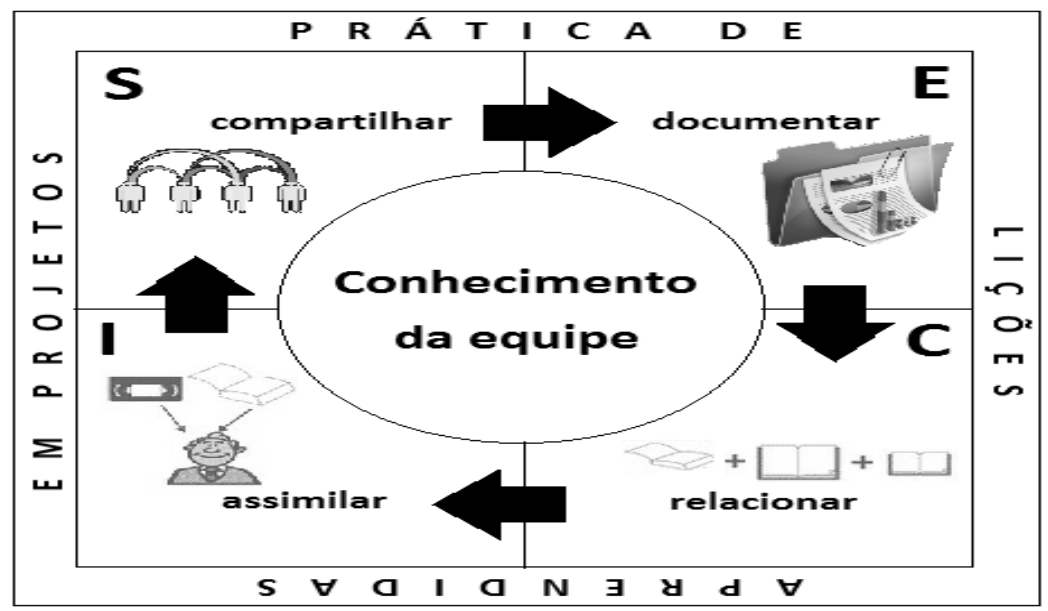

Fonte: elaborado pelos autores ${ }^{3}$

\footnotetext{
${ }^{3}$ Elaborado pelos autores, utilizando imagens e expressões de Universidade Federal de Alagoas (2016?).
} 
Este conhecimento externalizado pode então ser relacionado com outros conhecimentos advindos de lições aprendidas de outros projetos, gerando a combinação de conhecimentos. Por fim, a equipe pode assimilar novos conhecimentos (já externalizados e combinados em lições aprendidas anteriores) em um processo de internalização.

Na medida em que esta prática de lições aprendidas é estimulada na equipe, ela toma força e vai gradativamente aumentando o estoque de conhecimento dessa equipe, refletindo positivamente e diretamente no conhecimento organizacional da instituição.

Pode-se propor para novos estudos, a pesquisa das consequências da efetiva aplicação das práticas de lições aprendidas nos projetos de Consultoria Interna realizados por esta equipe. Da mesma forma, ferramentas de Gestão de Projetos e Gestão do Conhecimento mencionadas pelos entrevistados podem ser o foco de novos estudos aplicados à Gestão do Conhecimento no âmbito desta instituição ou de outras organizações do setor público.

\section{AGRADECIMENTOS}

Ao Professores Aparecida Laino Entriel, Márcia Machado e Saulo Barbará de Oliveira.

\section{REFERÊNCIAS}

ABRUCIO, L. F. Os avanços e os dilemas do modelo pós-burocrático: a reforma da Administração Pública à luz da experiência internacional recente. In: BRESSER PEREIRA, L. C.; SPINK, P. K. (Org.). Reforma do Estado e Administração Pública gerencial. Rio de Janeiro: FGV, 2005. p. 173-200.

BATISTA, F. F. Governo que Aprende: Gestão do Conhecimento em organizações do executivo federal. Brasília: IPEA, jun. 2004 (texto para discussão n. 1022).

BERGAN, J. R., NEUMANN II, A. J. Consultant Skill and efficiency and the implementation and outcomes of consultation. Journal of School Psycology, v. 14, n. 1, p. 3-13, 1976. BRASIL, A.; TBAREZ. A. Aplicação da Gestão do Conhecimento à Gestão de Projetos. 80f. Monografia (Pós-graduação lato Sensu - MBA em Projetos) - Fundação Getúlio Vargas, Programa FGV online, São Paulo, 2012.

BRESSER-PEREIRA, L. C. O modelo estrutural de gerência pública. Revista de Administração Pública, v. 42, n. 2, p. 391-410, 2008.

CASTRO, R. B. Eficácia, Eficiência e Efetividade na Administração Pública. In: ENANPAD, n. 30, 2006, Salvador, BA: Anpad, 2006. p. $1-11$.

CLELAND, D.I.; IRELAND, L.R. Gerenciamento de Projetos. 2. Ed. Rio de Janeiro: LTC, 2007. 
COELHO, E. M. Gestão do Conhecimento como sistema de gestão para o setor público. Revista do Serviço Público, ano 55, nº 1 e 2, p. 89-115, jan./jun. 2004.

DAFT, R. L. Administração. São Paulo: Cengage Learning, 2010.

DAVENPORT, T. H. \& PRUSAK, L. Conhecimento Empresarial: como as organizações gerenciam o seu capital intelectual. 14. ed. Rio de Janeiro: Campus, 2003.

DRUCKER, P. F. A sociedade pós-capitalista. São Paulo: Pioneira, 1993.

FERENHOF, H. A.; FORCELLINI, F. A.; VARVAKIS, G. Lições aprendidas: agregando valor ao gerenciamento de projetos. Revista de Gestão de Projetos - GeP, v. 4, n. 3, p. 197209, set./dez. 2013.

FLICK, U. Uma introdução à pesquisa qualitativa. 2. ed. Porto Alegre, RS: Artmed, 2004.

FREITAG, M. S. B. A Consultoria Interna como espaço para a conversão do conhecimento. REGE, São Paulo, v. 19, n. 1, p. 21-38, jan./mar., 2012.

GOUVEIA, F. F.; MONTALVÃO, J. B.; BRITO, M. S.. Gerenciamento de lições aprendidas: estudo de caso de projetos de integração laboratorial. $2010.79 \mathrm{f}$. Trabalho de conclusão de curso (MBA em Gerenciamento de Projetos) - Fundação Getúlio Vargas, Rio de Janeiro, 2010.

JOHRI, H. P.; COOPER, J. Chris; PROKOPENKO, J. Managing internal consulting organizations: a new paradigm. Advanced Management Journal, v. 63, n. 4, p. 4-10, Autumn, 1998. Disponível em: $<\mathrm{http}: / / \mathrm{www}$.freepatentsonline.com/article/SAM-AdvancedManagement-Journal/53450458.html> Acesso em: 11 abr. 2017.

KERZNER, H. Gestão de Projetos: as melhores práticas; tradução Lene Belon Ribeiro. - $2^{\text {a }}$ Ed. Porto Alegre: Bookman, 2006.

LACEY, M. Y. Internal consulting: perspectives on the process of planned change. Journal of Organizational Change Management. 8, n. 3, p. 75-84. 1995. Disponível em: $<$ http://www.emeraldinsight.com/doi/pdfplus/10.1108/09534819510090178> Acesso em: 05 mar. 2017.

MANCIA, L. T. S. Os desafios do modelo de Consultoria Interna: uma experiência gaúcha. 1997. 176 f. Dissertação (Mestrado em Administração) - Universidade Federal do Rio Grande do Sul/EA/PPGA, Porto Alegre, 1997.

MEIRELLES, H. L. Direito Administrativo Brasileiro. $39^{\text {a }}$ Ed. São Paulo: Editora Malheiros, 2013.

MELLO, C. A. B. Curso de direito administrativo. 28 ed. São Paulo: Malheiros, 2011. MILTON, N. The Lessons Learned Handbook: practical approaches to learning from experience. Oxford: Chandos Publishing, 2010. 
NONAKA, I; TAKEUCHI, H. Criação de Conhecimento na Empresa. $20^{\text {a }}$ Reimpressão. Rio de Janeiro: Elsevier, 1997.

. 2008. Gestão do Conhecimento. Porto Alegre: Bookman, 2008.

PROJECT MANAGEMENT INSTITUTE, PMI. Um Guia do Conjunto de Conhecimentos em Gerenciamentos de Projetos: Guia PMBOK. $5^{\text {a }}$ ed. Pennsylvania: Campus Boulevard, 2013.

REICH, R. B. O Trabalho das Nações - Preparando-se para o capitalismo no Século 21. São Paulo: Educator, 1994.

SABBAG, P. Y. Espirais do Conhecimento: ativando indivíduos, grupos e organizações. São Paulo: Saraiva, 2007.

SCHEIN, E. H. Consultoria de procedimentos. São Paulo: Edgard Blucher, 1972.

SECCHI, L. Modelos organizacionais e reformas da Administração Pública. Revista Administração Pública, Rio de Janeiro, v. 43, n. 02, mar./abr. 2009.

TERRA, J. C. C. Gestão do Conhecimento: o grande desafio empresarial - uma abordagem baseada no aprendizado e na criatividade. São Paulo: Negócio Editora, 2001.

THOMAS, D. R. A general inductive approach for analyzing qualitative evaluation data. American Journal of Evaluation. v. 27, n. 2, Jun. 2006.

TROCHIM, W. M. K. Outcome pattern matching and program theory. Evaluation and Program Planning. v.12, p.355-366, 1989.

VERGARA, S. C. Projetos e relatórios de pesquisa em administração. $10^{\mathrm{a}}$ ed. São Paulo: Atlas, 2009.

VIEIRA, N. S.; FEITOSA, M. G. G.; CORREIA, F. B. C. Dificuldades enfrentadas pelas comunidades de prática de consultores: o caso da comunidade de formação de consultores organizacionais. In: Encontro de Gestão de Pessoas e Relações de Trabalho (ENGPR), Anais eletrônicos. Natal: Anpad, 2007.

UNIVERSIDADE FEDERAL DE ALAGOAS (UFAL). Gestão do Conhecimento.

Disponível em: $<$ http://www.ufal.edu.br/gestaodoconhecimento/gestao-doconhecimento/gestao-do-conhecimento> Acesso em: 03 jan. 2017.

WATERMAN JR. R. H. Adhocracia: o poder para mudar. São Paulo: Pioneira, 1992. YIN, R. K. Estudo de caso; planejamento e métodos. 5a ed. Porto Alegre: Bookman, 2015. 